\title{
Creating a Global Public Inclusive Infrastructure (GPII)
}

\author{
Gregg C. Vanderheiden ${ }^{1, *}$, Jutta Treviranus ${ }^{2}$, Manuel Ortega-Moral ${ }^{3}$, \\ Matthias Peissner ${ }^{4}$, and Eva de Lera ${ }^{1}$ \\ ${ }^{1}$ Raising the Floor - International, Geneva, Switzerland \\ \{Gregg, Eva\} araising thefloor.org \\ ${ }^{2}$ OCAD University, Toronto, Ontario, Canada \\ jtreviranus@faculty.ocad.ca \\ ${ }^{3}$ Fundosa Technosite, Madrid, Spain \\ mortega@technosite.es \\ ${ }^{4}$ Fraunhofer Institute for Industrial Engineering IAO, Stuttgart, Germany \\ matthias.peissner@iao.fraunhofer.de
}

\begin{abstract}
The current accessibility ecosystem that develops and delivers both assistive technologies and access features in mainstream technologies is not able to keep up, provide the diversity of solutions needed, nor reach more that a small portion of those who need them. To address this a large scale effort was proposed to provide an infrastructure that would allow the ecosystem to evolve into a quite different and purportedly more effective and efficient ecosystem. This paper describes the infrastructure, reports on the progress in securing funding and implementing the various components of the infrastructure. A roadmap for the implementation and a timeline are provided along with a discussion of the major challenges going forward.
\end{abstract}

Keywords: Accessibility, Digital Literacy, Literacy, Ageing, Cloud Computing, GPII.

\section{$1 \quad$ Why Build a GPII? Why Is It Needed?}

There are a number of problems that led to the conclusion that a Global Public Inclusive Infrastructure (GPII) was needed.

The initial problem was identified during standards work on Web Accessibility. One of they key barriers to web access identified by the WCAG working group was the lack of assistive technologies that were affordable by those with limited resources, and that were powerful enough to be able to provide access to modern web content. An attempt to address this gap led to the formation of a consortium called the Raising the Floor Consortium -- whose mission was to identify or create low cost but capable assistive technologies to address the needs of this sector (to 'raise the floor' or base level of access technologies available to all and affordable by all.)

\footnotetext{
* Corresponding author. 
The consortium quickly realized however that the problem was more complicated and that just trying to create low cost solutions didn't really address many of the problems and, if attempted in isolation, might create others. The consortium also found that people with disabilities were not the only ones facing challenges in using the standard interfaces on mainstream Information and Communication Technologies (ICT), and other products with digital interfaces. There were four interrelated groups who all were experiencing barriers to use of ICT because of their inability to understand and/or use the standard interfaces. These include people who experienced barriers due to disability, literacy, digital literacy, and aging.

The problem in identifying, developing and delivering solutions to these groups was found to be quite severe. AT suppliers and clinicians estimated that only between $3 \%$ to $15 \%$ of people who need special interfaces were getting them. Although there were sometime hot debates as to which end of this range was more accurate, there was no one who estimated the penetration at higher than $15 \%$.

\subsection{Five Key Problems}

Five key problems were identified as the reason that such a small percentage of those who needed better interfaces were getting them.

1. Solutions don't exist for all types, degrees and combinations of disability, literacy, digital literacy and effects of aging;

a. Many groups are too small to be addressed by AT developers and vendors. They just can't afford the cost to develop for them both because of their small size and the difficult and expensive to solve problems they present.

2. Even when solutions do exist, people cannot find them - or don't even know to search for one;

b. Consumer are not aware that solutions exist that would address their problems so may not search. And those that do don't know the terms to use to describe what they need - or where to begin looking for it (other than 'google', which results in a massive redundant listing but no understanding).

3. Solutions costs too much (to develop/market/support, to buy, to deliver);

c. The high cost to develop and market, and their limited ability to reach people who need their specific solution, keeps the costs of solutions high; higher than many (most of thosewho need it?) can afford. Even for mainstream companies, the costs to train staff and build in solutions reduces willingness to do so (as does limited uptake/use by consumers who remain unaware of them. 
4. Solutions are too complicated;

d. Those solutions that are built-in to mainstream are too hard to find and set up and adjust. And for shared equipment, too hard to keep setting up and then un-setting for the next user.

e. AT are too hard to install; too complicated to use. They also often do the same things in unnecessarily different ways.

5. Solutions don't work across all of the devices and platforms that users encounter in education, employment, travel, and daily life.

f. Users encounter different devices they must use - but their solutions are almost all designed for just one platform. What do they do when the encounter all the other device they must use each day in different classes, at work, as they travel, at home, and in the community.

Further it was identified that these problems were interdependent.

- Developers/suppliers can't reduce costs (and thus prices) without reaching a broader audience, and without finding a less expensive way to develop, distribute, market and support the products. (They reported that they tried just reducing prices and it had little or no effect.)

- Low incidence groups cost even more to develop for - and without the ability to reach them companies won't/can't take these on.

- Complexity and cost keep many away that do hear about solutions. But the solutions are not affordable or understandable/ usable for them.

- Solutions that might work are not available on all the platforms/device the people have to use. So they don't address the access problem for these people.

- Developers/vendors can't afford to develop solutions on all of the platforms because of the cost - and low sales volume.

- Many who need things, and could use and pay for what is available, don't know about them - so even these sales are lost.

To address this situation it appears that a fundamentally change in the way Accessibility was approached is required. What was proposed was to create some type of common infrastructure that everyone could use that would:

- a) simplify finding and using AT and other access solutions, and

- b) lower the cost to develop, market, and support AT so that it can cost less to consumers,

- c) create a common framework and cross-platform components to reduce duplication of effort and increase compatibility,

- d) and make it easier to connect developers/vendors with consumers, especially for smaller market solutions.

- e) make it easier and lower costs for mainstream companies to build access into their products to meet their own and customer accessibility requirements. 
Reexamining the issue from the broader perspective also made it clear that the issues couldn't be addressed with the ecosystem, as it currently existed. But replacing the ecosystem is not an option either. So the focus of the consortium shifted to identifying the key contributing problems, exploring why the current ecosystem couldn't meet them, and determining how to grow or strengthen the ecosystem so that it could.

\section{The Global Public Inclusive Infrastructure (GPII)}

The GPII is an infrastructure that uses the cloud and the capabilities of the ICT to help evolve the access ecosystem so that it is better able to affordably reach and server all the people facing barriers to digital devices due to disability, literacy, digital literacy and/or aging.

\subsection{Goals and Components of the GPII}

The GPII cannot and does not attempt to directly address the problem identified in the introduction to this paper. Rather it is an infrastructure that is being designed and built to facilitate the efforts of others in the ecosystem (developers, vendors, clinicians, families, funders, etc.) in meeting these needs and addressing these challenges. That is, the goal of the GPII is not to solve but to facilitate or to make it easier for others to solve the problems identified above and to deliver affordable solutions to those who need them.

The role and goal of the Raising the Floor Consortium then is to create this global, publicly available, infrastructure to facilitate inclusion (the GPII) that can

1. Make it easier...

...for people to find solutions to their access problems

...for people to instantly invoke what they need on any device the person encounters.

...for developers to create new solutions.

2. Make it cost less...

...to create new solutions.

...to deliver new and existing solutions.

...to support new and existing solutions.

and in this way - to lower the cost to users.

3. Make solutions work across platforms so that...

...the solutions a person needs appear on any device they encounter.

...products work in a fashion that is familiar and understandable to each individual. 
...solutions appear even on devices a person has never encountered before, instantly, and without the person having to understand how it is done.

4. Make solutions available nationally and internationally

...in all of the languages and cultures within, and across, nations.

Figure 1 provides a diagram of the major components of the planned GPII, organized by the three major functions of the GPII.

1. Making it easy to discover what will help a person access ICT anything with a digital interfaces in general;

2. Making it possible to invoke the features or services a person needs anywhere, anytime, on any device they encounter; and

3. Making it easer, faster, and less expensive to develop, distribute, market, and support access solutions (devices and services - including both assistive technologies and features on mainstream products).

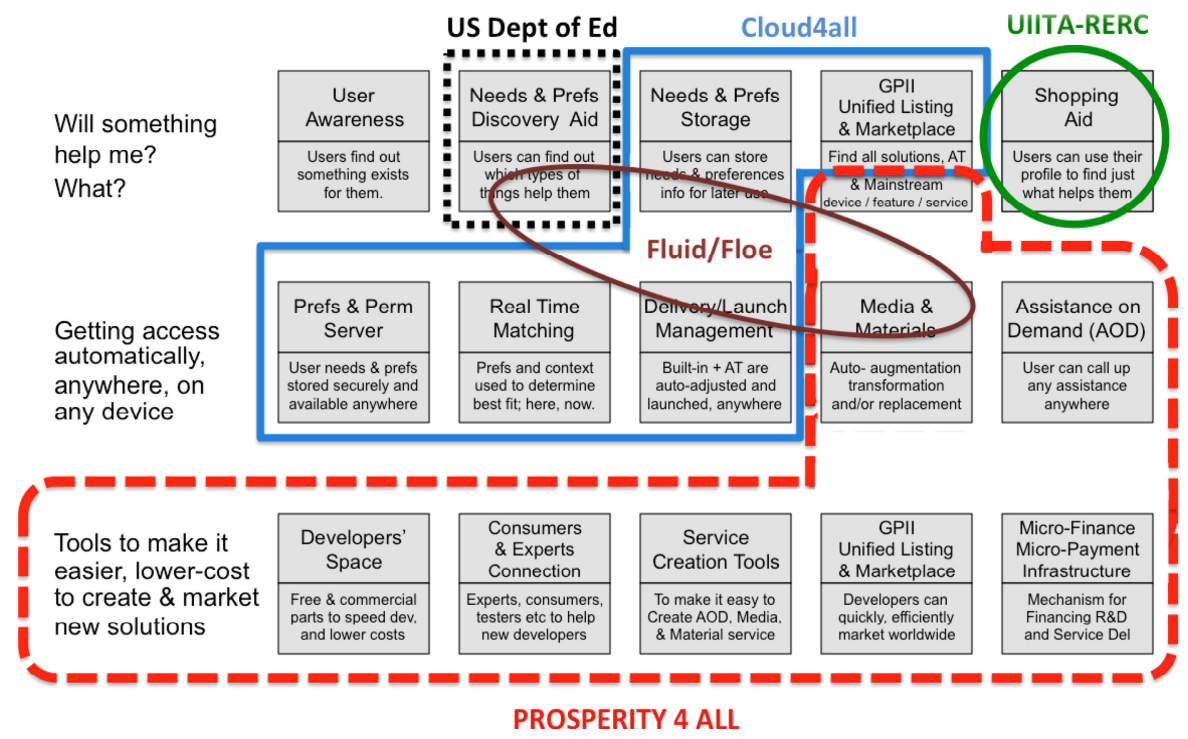

Fig. 1. Major Components of the GPII and the grants providing initial R\&D on them

\section{$2.2 \quad$ Vision}

The vision of the GPII is to provide an infrastructure that would create a world where everyone, even those with disabilities, or who cannot read, or who cannot deal with 
technical complexity of any type, and those who are losing sensory abilities or the ability to learn new things due to aging, are able to use any device they encounter.

Any device they approach instantly and automatically changes its digital interface into one that they can use, and that looks and operates in a familiar way.

Any documents sent to them arrive in a form that they can use (print, large print, braille, audio file, accessible ebook, etc) no matter what form it was in when it was sent to them.

Media (movies, audio files, etc) come with captions or video description or text alternatives if they need them in order to use or understand the media.

People with cognitive disabilities for whom technology cannot yet address their needs can call up Assistance on Demand to help them with any interface or documents or media they encounter.

Anyone can set up an "Assistance on Demand" service for anyone who needs it for any reason; visual, hearing, physical or cognitive. They can set one up out of friends and family members, or set one up with professionals, or both.

Assistive technologies are available as services (pay-as-you-go) so that people are free to try new technologies and switch to them if they are better. Or people with progressive conditions can easily change their solutions as their conditions change.

Creating new solutions and getting them to market is easy enough that there is a rich set of solutions available including solutions for very small populations. Consumers and practitioners are also able to become directly involved in the specification and development of new solutions.

Consumer are aware that solutions exist and it is easy for them to find the solutions that best meet their needs.

Solutions are available that are affordable to all who need them in all countries. These solutions are good enough to provide at least full basic access to the technologies they encounter.

\section{Who Is Building the GPII}

\subsection{NPII to GPII and the Establishment of the Raising the Floor Consortium and Raising the Floor - International}

Although the initial concept for the GPII began in the United States as a National Public Inclusive Infrastructure (NPII), the concept quickly spread and matured, and within months was rechristened the Global Public Inclusive Infrastructure (GPII). To reflect and facilitate the international nature of efforts, and the strong support and contributions in Europe, the headquarters for the consortium was established as a nonprofit organization in Geneva. Switzerland. Raising the Floor - International in Geneva now serves as the legal entity and the coordinating point for the Raising the Floor Consortium that is building the GPII. The Consortium now includes over 50 companies and organizations from over a dozen different countries. A list of the consortium members can be found at http://raisingthefloor.org. 
The GPII is currently under construction with funding from a broad base of funders.

- The National Institute on Disability and Rehabilitation Research, US Dept. of Education under Grants H133E080022 (RERC-IT) and H133E130028 (UIITA-RERC) supported the initial formation of the Raising the Floor Consortium, the coordination of the overall effort, development of the shopping aid, and the first deployment of the GPII in libraries in the US.

- The European Union's Seventh Framework Programme (FP7/2007-2013) grant agreement 289016 (Cloud4all) is funding the development of the core elements for the "auto-personalization from preferences" (APfP) infrastructure including the preference semantic infrastructure, the GPII preference server, the federated repository of information on assistive technologies, the matchmaking architecture, the launch and settings handlers and other run time components and more.

- US Dept. of Education under contract ED-OSE-12-D-0013 (Preferences for Global Access), is funding the development of Needs \& Preferences Tools Architecture and the First Discovery Aid.

- The European Union's Seventh Framework Programme (FP7/2007-2013) grant agreement 610510 (Prosperity4All) is funding most of the

- The Flora Hewlett Foundation, the Ontario Ministry of Research and Innovation, the Canadian Foundation for Innovation, has funded much of the foundation research in personalization and the Canadian government the Canadian portion of the Cloud4all work (above).

- The Adobe Foundation, provided the early funding to support the formation of the Raising the Floor Consortium and Raising the Floor - International.

- The Consumer Electronics Association Foundation, IBM, Microsoft and others have provided matching and in-kind contributions to facilitate the GPII work in the Cloud4all and Prosperity4All projects.

- The Raising the Floor Consortium members themselves have also provided matching funding and in-kind funding to support the work.

Figure 1 above shows how some of the major grants relate to the GPII components.

\section{GPII Roadmap}

The initial research and development of the GPII is being done under support from the Canadian, US, and European governments, and from the foundations, companies, and organizations listed or linked to above. This development work includes implementation and testing of the GPII by companies in their products. Implementations being carried out as part of these R\&D activities by AT companies, mainstream companies and research organizations include:

- 3 Operating Systems - including Windows, Linux, and Android

- 3 Browsers - including IE, Firefox and Chrome

- 2 Phones - Smartphones (Android) and Simple Feature Phones (Java)

- 3 Embedded Devices - Kiosk, Train Ticket Machine, PixelSense 
- 2 Home - DTV, Smart house simulation

- 2 Web Apps - Online Banking Simulation, Social Network

- 3 Web/server based AT - WebAnywhere, SAToGo, Browsealoud

- 4 Installed AT - NVDA, ReadWrite Gold, SuperNova, Maavis

- 2 Phone AT - Mobile Accessibility, eCtouch/eCmobile,

( 4 of these were not planned or funded but were spontaneous by the companies involved. This will continue in parallel with the funded work)

This development work will be followed by pilot implementations in the field. The first of these is planned for libraries and just been funded. Other implementations under exploration (but for which funding had not yet been secured) include public access points, educational testing, schools, private homes, travel kiosks, banks (websites and terminals), ecommerce, public service agencies, community centers, and private companies. A key goal of the pilots is the gathering of metrics on the impact of the GPII in these environments both in terms of increased benefit and decreased cost.

The pilots will then be followed by full rollouts in the different domains where the pilots demonstrate the GPII is ready and beneficial. These will be done in a staged fashion - with timing based on the ability to support them.

In parallel with the GPII "auto-personalization from preferences" (APfP) rollouts, the GPII information services will be implemented. This includes the Unified Listing and Marketplace as well as the DeveloperSpace and its resources. Work on these is funded through 3 grants (each covering different parts) plus matching funding from the Consumer Electronics Association Foundation.

\section{$5 \quad$ Timeline}

Initial rollouts in libraries on a development level are expected by next year 2015 . This will be followed by full rollouts in test public and university libraries starting the next year. Rollouts into additional libraries are expected at that year as well.

In parallel with the library rollouts, we will be enabling library patrons to be using the GPII on their personal and home computers as well. This will be the first general deployment of the GPII in the wild. This individual deployment will proceed from there based on the success and ability to provide support.

The Unified Listing is expected to be up and in operation internationally by the end of 2014 or the beginning of 2015. The shopping/Alerting aid is expected to come online for preliminary testing in 2015 with broader deployment in 2016.

The Marketplace is expected to come online in 2016 or early 2017 for initial testing and general use a year later.

\section{Challenges}

The challenges in this endeavor are significant. Nothing of this type or scale has ever been attempted. On the plus side, there is almost unanimity that something is needed 
and the approach on its face seems to be widely accepted as good and powerful approach if it can be pulled off. There is also a very large number of organizations that have gotten behind it and investing themselves in its development and implementation.

On the other side, the infrastructure has a lot of moving parts. Every attempt is being made to both simplify the architectures as much as possible, and to work on an incremental fashion, with basic services implemented first - and more advanced ones added over time. The coordination and planning however are significant challenges.

A second challenge is scaling. Again everything is being designed to be scalable, but until it is deployed and in wide use, it is difficult to anticipate or simulate the loads and unexpected behaviors of the users. Yet when this is done, there will be people depending on it - so failure has significant implications for individuals. The model to be used for the rollout will be important here.

Adoption and incorporation of GPII compatibility in assistive technologies and mainstream products is essential to the GPII's success. Here a chicken and egg situation arises. The GPII works well only if it is deployed widely and works with the access technologies. Until it is deployed however there is little incentive to make access technologies compatible with it. The strategy being used to address this is a combination of selecting domains such as the libraries where there is a demonstrated need and a containable environment. There is also high motivation for access technology vendors to want to have their products work with the system. We are also identifying particular assistive technology applications where the GPII provides unique advantages even for individual vendors. Finally we are developing tools to make it easy to build GPII compatibility into their products. Still this is a definite challenge area.

Funding and sustainability is a fourth challenge. We have had two offers to completely fund the infrastructure by industry. When we explained that they may be less interested because there were two key rules 1) that there could be no data-mining of the needs and preference information on any of the users, and 2) the needs and preference information could not be used to direct advertising (otherwise if we were an insurance company we would like to have our advertising sent to all those who were easily confused) both companies agreed and withdrew their offer. Operating such an infrastructure as a public trust without monetizing it in any way that might be a disadvantage to the users, creates some sustainability challenges. Fortunately, the operation of the "auto-personalization from preferences" (APfP) capability is very light on both server CPU and bandwidth. With continually dropping IT costs, and no human service (other than system maintenance) involved in the infrastructure, the overall cost once up should be nominal. If the service is indeed beneficial, then the cost should be dwarfed by the benefit. To secure funding however this needs to be demonstrated and proven.

\section{Conclusion}

The Global Public Inclusive Infrastructure (GPII) is a novel and ambitious attempt to take a systematic and holistic approach to addressing a set of severe and growing 
problems regarding the ability to provide usable interfaces to those who cannot use standard interfaces well or at all. Because we are moving rapidly to a technology based society, incorporating digital interfaces into every aspect of life and into every device around us (including those needed for activities of daily living), the inability to provide usable interfaces to all but a fraction of those who need is as significant challenge and an important priority.

\section{Participation}

The effort to build the GPII is an open one and any and all are invited to join in. People with every type of skill are needed. The efforts can be followed on http://GPII.net, http://raisingthefloor.org, http://Cloud4all.info and http://Prosperity4All.eu. There are also two dozen papers in these proceedings on different aspects of the GPII work. For those interested in more in-depth information, or who would like to join in, the work of the consortium is conducted in public on the WIKI at http://wiki.gpii.net and the lists at http://lists.gpii.net.

Acknowledgments. This research was funded by the European Union's Seventh Framework Programme (FP7/2007-2013) grant agreement 289016 (Cloud4all) and 610510 (Prosperity4All), by the National Institute on Disability and Rehabilitation Research, US Dept. of Education under Grants H133E080022 (RERC-IT) and H133E130028 (UIITA-RERC) and contract ED-OSE-12-D-0013 (Preferences for Global Access), by the Flora Hewlett Foundation, the Ontario Ministry of Research and Innovation, and the Canadian Foundation for Innovation, by Adobe Foundation, and the Consumer Electronics Association Foundation, with support from IBM, Microsoft, and the participating partners. The opinions and results herein are those of the authors and not necessarily those of the funding agencies. 